\title{
DOCTRINA
}

\section{El derecho humano al medioambiente: Nuevos avances en su comprensión en América Latina y el Caribe}

\author{
Human right to the environment: New advances in its comprehension \\ in Latin America and the Caribbean
}

\author{
Ezio Costa Cordella \\ ONG Fima, Chile \\ Gabriela Burdiles Perucci \\ ONG Fima, Chile
}

\begin{abstract}
RESUMEN Este artículo analiza el contenido normativo del derecho humano a vivir en un medioambiente sano, a partir del análisis de la opinión consultiva $23 / 17$ de la Corte Interamericana de Derechos Humanos. La Corte concibe este derecho, desde una perspectiva antropocéntrica, como un derecho humano autónomo, y establece sus relaciones con otros derechos, además de analizar su estructura, asociándolo con deberes de prevención y precaución. Por otra parte, el reconocimiento de ese derecho requiere de mecanismos concretos para garantizar su pleno ejercicio, dentro de los cuales están el acceso a la información, a la participación pública en la toma de decisiones ambientales y el acceso a la justicia ambiental (los «derechos de acceso»), que figuran en el Acuerdo de Escazú.
\end{abstract}

PALABRAS CLAVE Medioambiente, derecho a un medioambiente sano, América Latina, opinión consultiva, Corte Interamericana de Derechos Humanos.

ABSTRACT This article analyzes the normative content of the human right to live in a healthy environment, based on the analysis of Advisory Opinion 23/17 of the Inter-American Human Rights Court. The Court conceives this right, from an anthropocentric perspective, as an autonomous human right, and establishes its relations with other rights, in addition to analyzing its structure as a human right, associating it with preventive and precautionary duties. On the other hand, the recognition of this right requires specific mechanisms to guarantee its full exercise, among which are access to information, public participation in environmental decision making and access to en- 
vironmental justice (the so-called "access rights"), which are contained in the Escazú Agreement.

KEYWORDS Environment, right to healthy environment, Latin America, Consultative Opinion, Interamerican Human Rights Court.

\section{Introducción}

El presente artículo tiene como objetivo observar, a la luz de la opinión consultiva OC-23/17 de la Corte Interamericana de Derechos Humanos (Corte IDH), en la que se solicitó a la Corte que se pronunciase acerca de la interpretación del Pacto de San José de Costa Rica en relación con otros tratados en materia ambiental, en el tema de las obligaciones internacionales de los Estados en materia de prevención, precaución y mitigación de daños en el medioambiente que puedan afectar a otros Estados. ${ }^{1}$ De esta opinión derivó una doctrina sobre la relación del derecho al medioambiente sano y los derechos humanos. A partir de lo señalado, se revisarán algunas de las principales variables de la protección legal, y en especial del contenido del derecho a vivir en un medioambiente sano (o libre de contaminación).

Así, por un lado, se verá cómo la opinión de la Corte IDH desarrolla el contenido de este derecho, relacionándolo con el resguardo y ejercicio de otros derechos humanos, discusión de corte antropocentrista; y, por otro lado, los lineamientos y mecanismos que la misma Corte señala como necesarios para dar garantizar el pleno ejercicio de estos derechos, los cuales se encuentran recogidos en el instrumento regional del Acuerdo de Escazú.

El argumento general que se desarrollará pretende analizar el estado actual de la protección de este derecho en Chile, y los avances esperados, tanto a propósito de esta opinión consultiva, como de la firma del Acuerdo de Escazú, sobre el acceso a la información, la participación pública y el acceso a la justicia en asuntos ambientales en América Latina y el Caribe.

1. Corte Interamericana de Derechos Humanos, opinión consultiva OC-23/17, 15 de noviembre de 2017, solicitada por Colombia, titulada oficialmente «Obligaciones estatales en relación con el medio ambiente en el marco de la protección y garantía de los derechos a la vida y a la integridad física: Interpretación y alcance de los artículos 4.1 y 5.1, en relación con los artículos 1.1. y 2 de la Convención Americana sobre Derechos Humanos». 


\section{El derecho a vivir en un medioambiente sano}

\section{Consagración y características en el derecho internacional}

La preocupación por el medioambiente como objeto del derecho es una cuestión reciente, pues recién en 1970 se puso en la agenda la necesidad de preocuparnos del espacio común que sustenta la vida en el planeta. Pronto la discusión se volvió una discusión de derechos humanos, es probable que por un problema de adecuación de las herramientas existentes al problema en cuestión, pero también porque parece evidente que la protección del medioambiente es, también, la protección de las personas.

Este enfoque, sin embargo, no ha estado exento de críticas, que se enmarcan en un debate sobre la protección ambiental desde una visión más o menos antropocéntrica. Como reconoce Aristegui (2010: 24), existe una corriente de autores que critica la conceptualización del medioambiente como un derecho humano por la negación del valor de otras vidas (flora y fauna) o por existir medios más pertinentes y eficaces de su protección (normas de comercio, por ejemplo).

Es desde los principios planteados en la Declaración de Estocolmo en 1972 que se extrajo como consecuencia lógica que algunos países comenzaran a incorporar en sus constituciones la garantía de vivir en un medioambiente sano. La tendencia a la consagración constitucional comenzó con la Constitución suiza de 1971, que en su artículo 24 septies le entregaba a la confederación los poderes regulatorios relativos a la protección del medioambiente. En seguida, las constituciones de Grecia de 1975, Portugal de 1976 y España de 1978, también incorporaron, con diversas redacciones, la protección del medioambiente (Jaria i Manzano, 2011: 184-186). En América Latina, la Constitución chilena de 1980 fue la primera en incorporar la cuestión ambiental, específicamente como un derecho fundamental y en el modo que se revisará más adelante.

Junto con la Constitución chilena, muchas otras fueron incorporando la protección del medioambiente bajo la fórmula de la consagración de un derecho fundamental. Curiosamente, sin embargo, ello no obedece a una recepción directa de los tratados internacionales de derechos humanos, pues en su mayoría ellos no contienen esta garantía. El derecho al medioambiente no se encuentra incorporado en la Declaración Universal de Derechos Humanos, ni en el Pacto de San José, por ejemplo. Sí está reconocido en el Protocolo de San Salvador, instrumento acordado en 1988 —que Chile no ha ratificado-, bajo la fórmula del artículo 11, que señala: «Derecho a un medioambiente sano. 1) Toda persona tiene derecho a vivir en un medio ambiente sano y a contar con servicios públicos básicos. 2) Los Estados parte promoverán la protección, preservación y mejoramiento del medioambiente».

La Convención Europea de Derechos Humanos tampoco contiene una provisión específica relativa al medioambiente, aunque ello no ha impedido que la Corte conozca de cuestiones relacionadas con su protección, lo que ha sido posible gracias a interpretaciones que lo incluyen en su mayoría dentro del derecho a la privacidad, 
aunque también hay casos en que se le ha relacionado con las garantías judiciales y con el derecho a la información (Bonine y Kravchenko, 2012: 24).

Por último, la Carta Africana de los Derechos de los Pueblos, en su artículo 24, estableció el derecho humano a un «ambiente generalmente satisfactorio para el desarrollo» en 1981. Luego, en 2003, la Convención Africana sobre la conservación de la naturaleza y los recursos naturales pone al mismo derecho en un principio y desarrolla las obligaciones de los estados para proteger la naturaleza y los recursos naturales, así como el derecho al medioambiente. De manera notable, esta última Convención se refiere más que nada a los elementos del medioambiente y las obligaciones de los Estados en relación con dichos elementos.

De este breve resumen, quisiéramos resaltar lo interesante que resulta el modo en que el derecho al medioambiente se ha construido e incorporado entre los instrumentos de derechos humanos, pues obedece a una construcción eminentemente desde las bases de la sociedad, que a raíz de su relevancia para el desarrollo de la vida y de otros derechos, se ha ido de ha poco incorporando en leyes y constituciones nacionales como primer paso; $y$ que si bien tiene algunas manifestaciones en el derecho internacional con vinculatoriedad, es un camino que apenas empieza a recorrerse, y del cual instrumentos como los que se comentarán más adelante resultan fundamentales. En la actualidad, más de 100 constituciones contienen el derecho al medioambiente, con diferentes redacciones (PNUMA, 2014).

En este contexto, es relevante la pregunta sobre cuál es la naturaleza del derecho al medioambiente. Así, Boyd (2011: 21) se pregunta si es un derecho humano, para concluir luego que en efecto lo es, basado en que reuniría tres condiciones: i) ser universal; ii) tener una base moral; y iii) que su intención básica es la de asegurar la dignidad humana. Sobre este entendimiento, veremos en la siguiente sección cómo es que se incorporó el derecho en Chile y qué comprensión tenemos de él.

\section{Contenido y alcance del derecho a vivir en un medioambiente} libre de contaminación en Chile

A pesar de que la doctrina y jurisprudencia chilena han avanzado en el sentido de flexibilizar el contenido de la garantía del artículo 19 numeral 8 de la Constitución, para adecuarlo a la lógica de los derechos humanos, sigue existiendo de tanto en tanto una discusión bizantina sobre lo que en verdad abarca el derecho en cuestión. Este debate tiene un sustento histórico y literal, que no puede sino suscitarnos críticas sobre la formulación del derecho en nuestra Constitución, que ha dado pie a estas divergencias y, por lo tanto, a la posibilidad de que se aplique en desmedro del derecho humano al medioambiente.

Nos parece posible detectar tres tipos de doctrinas que se vinculan con este artículo. El primero es de tipo reduccionista e intenta acotar el ámbito de operación 
del derecho a vivir en un medioambiente libre de contaminación, ya sea desde la perspectiva de volverlo radicalmente antropocéntrico, ya sea desde la postura de vaciarlo de contenido mediante la utilización de una lógica formalista para interpretar el vocablo contaminación.

La primera postura es reconocida por la doctrina en los escritos de Bertelsen Repetto (1998: 139-174), quien, analizando la procedencia del recurso de protección en la materia, considera que éste es solo procedente en cuanto el derecho a vivir en un medioambiente libre de contaminación sea vulnerado en su faz de derecho subjetivo público, que el mismo autor diferencia de una faz que llama «de aspiración constitucional», y que es la dimensión de derecho social de esta garantía.

Es del caso señalar que el autor antes referido sí reconoce la dimensión social del derecho en cuestión, pero no la hace exigible. En línea con cierta doctrina constitucionalista de finales del siglo XX, pretende que los derechos sociales presentes en la constitución solo son cartas de navegación para el Estado. Interesante es, por lo tanto, la manera en que Vásquez trata esta interpretación, pues la clasifica en un artículo de revisión del derecho en cuestión como parte de su pasado, y retruca que:

Sin perjuicio de lo señalado precedentemente, es posible afirmar en la actualidad y a la luz de la legislación ambiental y de la jurisprudencia de los últimos años, que su naturaleza es la de una garantía social, económica y cultural, en cuanto se relaciona con el deber de proteger un ambiente común, un patrimonio natural vital y de bienestar no solo para los individuos, sino de toda la comunidad nacional y, hoy día, frente a un mayor desarrollo de la consciencia ante los riesgos y desafíos de la crisis ecológica global, se comienza a comprender en una dimensión de alcance mundial o planetaria (Vásquez Márquez, 2014: 150).

La segunda postura dentro de esta doctrina ha sido tradicionalmente usada como teoría de control por la doctrina del derecho ambiental, pues sin perjuicio de que es usada por los abogados litigantes que defienden a potenciales contaminantes, esa defensa tiene poca cabida en la doctrina, e incluso la jurisprudencia del Tribunal Constitucional que la utiliza matiza su pertinencia. Es el caso de la causa rol 577, en que se requirió la inconstitucionalidad de una norma de emisión. Para Guzmán Rosen (2012: 55), esta sería una causa que da cuenta de la doctrina formalista y restrictiva de la interpretación del vocablo contaminación, pues expresa el fallo en su considerando decimotercero que, «mientras no se aprueben las normas de calidad ambiental respectivas que determinen objetivamente los parámetros dentro de los cuales es admisible en el ambiente una sustancia o elemento, no corresponde hablar de contaminación».2

Sin embargo, el mismo considerando continúa y señala que lo anterior será así, «a menos que se acredite inequívocamente la presencia en el ambiente de un con-

2. Sentencia del Tribunal Constitucional, rol 557-2016, considerando 13. 
taminante, en términos tales que constituya un riesgo cierto a la vida, la salud de la población, a la conservación del ambiente o la preservación de la naturaleza, o bien que exista una situación de pública e indiscutida notoriedad de la presencia gravemente nociva en el ambiente de un contaminante». Es decir, aun cuando el concepto legal de contaminación podría ser un indicador útil a la hora de definir su existencia, no es el único y podría probarse la existencia de contaminación de todas las maneras que luego expresa el Tribunal, manteniéndose entonces como un concepto eminentemente abierto.

Una doctrina mayoritaria es expansionista de este derecho, mediante la interpretación de los vocablos del mismo artículo, en perspectiva de ampliar su ámbito de acción. En esta línea encontramos por ejemplo a Bermúdez Soto (2000: 14), para quien el derecho a vivir en un medioambiente libre de contaminación supone una vida puesta en movimiento $y$, por lo tanto, hay una distinción importante con el mero derecho a la vida. De acuerdo con el autor, lo que en realidad resguardaría el derecho es la calidad de vida de las personas. Señala el autor que

hay que agregar que dicha cualidad que comporta un medioambiente libre de contaminación se refiere a que esa vida que se desarrolla, esa existencia humana, sea cualitativamente buena desde la perspectiva de los niveles ambientales. Es decir, el 19 numeral 8 CPR, permite que la persona humana pueda desarrollarse con unos determinados recursos o medios de subsistencia, en definitiva «vivir», en unas ciertas condiciones las cuales son otorgadas por ese objeto que se llama medioambiente libre de contaminación (Bermúdez Soto, 2000: 14).

Por último, existe una doctrina que es expresamente crítica de la manera en que se consagró el derecho al medioambiente en nuestra Constitución, y que por lo tanto aboga por cambiarlo. Es el caso de Aguilar, quien observando la forma en que el derecho ha sido consagrado en otras constituciones, expresa:

Entonces, se podría argumentar que otros términos, como el derecho a un medioambiente sano o saludable, adecuado y ecológicamente equilibrado, apto para el desarrollo y el bienestar de las personas, resultan más convenientes por dos razones fundamentales. Primero, porque centran la preocupación del derecho en el medioambiente. Segundo, porque amplían el ámbito de acción y, por lo tanto, de protección de este derecho, a formas de degradación del medioambiente diversas de la contaminación, tal como es entendida esta última en el orden jurídico chileno (Aguilar Cavallo, 2016: 368-369).

Aguilar, sin embargo, constituye una mixtura entre la doctrina expansionista y la crítica, pues si bien formula su contrariedad con la manera en que está consagrado el derecho en nuestra Constitución, también cree que de la lectura de la doctrina y jurisprudencia es posible extraer un concepto mucho más amplio: 
Esta visión amplia implicaría considerar como parte integrante del contenido de este derecho, esto es, de la extensión material del poder que puede ejercer y exigir el o los titulares del mismo, a la vida y la salud de las personas, en su vertiente de vida digna, calidad de vida, bienestar y buen vivir. Junto a ello es indispensable la consideración del principio de desarrollo sustentable en conexión indivisible con el derecho al desarrollo dentro de la materia cubierta por el derecho a un medioambiente sano, adecuado, ecológicamente equilibrado y apto para el desarrollo y el bienestar de las personas (Aguilar Cavallo, 2016: 407).

En lo que nos interesa, esta discusión da cuenta de la incertidumbre que aún existe en la doctrina y la jurisprudencia nacional sobre el derecho al medioambiente como un derecho humano autónomo, cuestión que en especial influye sobre la comprensión del ámbito de extensión del derecho y el objeto protegido. Es por esto que tanto la opinión de la Corte Interamericana de Derechos Humanos en la materia como el contenido del Acuerdo de Escazú constituyen un avance fundamental en la comprensión del derecho humano al medioambiente en Chile y, en general, en América Latina y el Caribe, como veremos en las secciones siguientes.

\section{La opinión consultiva de la Corte IDH: Principales avances en materia de protección del medioambiente}

\section{Contexto}

El 14 de marzo de 2016, Colombia presentó, amparado en el artículo 64 de la Convención Americana de Derechos Humanos, una solicitud de opinión consultiva a la Corte IDH sobre la degradación ambiental del mar Caribe y las responsabilidades de los Estados en relación con los habitantes de Estados vecinos. Señala la Corte que

el Estado solicitante busca que la Corte determine cómo se debe interpretar el Pacto de San José en relación con otros tratados en materia ambiental que buscan proteger zonas específicas, como es el caso del Convenio para la Protección y el Desarrollo del Medio Marino en la Región del Gran Caribe, con relación a la construcción de grandes obras de infraestructura en Estados parte de estos tratados y las respectivas obligaciones internacionales en materia de prevención, precaución, mitigación del daño y de cooperación entre los Estados que se pueden ver afectados (opinión consultiva OC-23/17, párrafo 1).

Existe cierto nivel de especulación sobre la real motivación de la opinión consultiva, pues ella se produce en medio de una disputa territorial entre el Estado de Colombia y el de Nicaragua. ${ }^{3}$ Sin embargo, esto no es relevante para efectos de lo que

3. Véase, por ejemplo, Nicolás Boeglin, «Ambiente y derechos humanos: Algunos apuntes sobre la opinión consultiva OC-23 de la Corte Interamericana de Derechos Humanos (Corte IDH)», Piensa 
nos interesa, que es la doctrina que estableció la Corte IDH a propósito de la consulta en cuestión, por lo que nos centraremos en su fondo.

En efecto, si bien las consultas planteadas por Colombia eran precisas y condicionadas, la Corte consideró que tiene competencias para responder la consulta modificando la pregunta en cuanto a sus especificidades, por lo que señaló:

Esta Corte ha indicado que, en aras del interés general que revisten sus opiniones consultivas, no procede limitar el alcance de las mismas a unos Estados específicos. Las cuestiones planteadas en la solicitud trascienden el interés de los Estados parte del Convenio de Cartagena y son de importancia para todos los Estados del planeta. Por tanto, este Tribunal considera que no corresponde limitar su respuesta al ámbito de aplicación del Convenio de Cartagena. Además, tomando en cuenta la relevancia del medioambiente en su totalidad para la protección de los derechos humanos, tampoco estima pertinente limitar su respuesta al medioambiente marino. En la presente opinión, la Corte se pronunciará sobre las obligaciones estatales en materia ambiental que se relacionan más íntimamente con la protección de derechos humanos, función principal de este Tribunal, por lo cual se referirá a las obligaciones ambientales que se derivan de las obligaciones de respetar y garantizar los derechos humanos (opinión consultiva OC-23/17, párrafo 17).

Así las cosas, las interpretaciones y avances que se revisarán en lo sucesivo no están limitados de manera alguna a la consulta planteada por Colombia, salvo en el hecho de que es dicha consulta la que produjo el procedimiento no contencioso que concluiría con la más importante resolución en materia de derechos humanos y medioambiente que ha emitido la Corte IDH, instrumento que debiera influir positivamente en la comprensión que el derecho al medioambiente tiene en América Latina y en Chile.

\section{Relación entre medioambiente y derechos humanos}

El primer punto que es tratado por la Corte es la relación entre los derechos humanos y el medioambiente, y la primera novedad interesante se produce en este contexto. En efecto, no solo la Corte considera que hay una innegable relación entre estos dos elementos, sino que además considera en forma expresa que el cambio climático, entre otros fenómenos de degradación del ecosistema por causa humana, afectan el goce efectivo de los derechos humanos (párrafo 21).

La Corte no se refiere al derecho al medioambiente como tal en un principio, probablemente porque no está contenido en el Pacto de San José, que es objeto de la consulta. Se refiere más bien a cómo la calidad del medioambiente en sí mismo es un requisito fundamental para el desarrollo digno de la vida humana, y utiliza un

Chile, 13 de febrero de 2018, disponible en http://bit.ly/2SIpsgq. 
sistema de fuentes variadas para arribar a dicha conclusión. Cita a la Corte Europea de Derechos Humanos, al Experto Independiente para el Medio Ambiente y los Derechos Humanos de Naciones Unidas, a la Declaración de Río de 1992 y a la Agenda 2030 para el Desarrollo Sustentable de Naciones Unidas (párrafos 22-25).

Finalizada la revisión de la conexión entre la degradación ambiental y los derechos humanos, la Corte IDH concluye que es esa relación la que tiene como consecuencia tanto que se reconozca, por una parte, un derecho autónomo al medioambiente sano, $y$, por otra, una interconexión entre el medioambiente y otros derechos humanos. El primer derecho vulnerado, evidentemente, sería el derecho a un medioambiente sano, que como hemos señalado, está contenido en el Protocolo de San Salvador, y en la mayoría de las constituciones de América.

En su punto 57, la Corte conceptualiza este derecho y su naturaleza como:

El derecho humano a un medioambiente sano se ha entendido como un derecho con connotaciones tanto individuales como colectivas. En su dimensión colectiva, el derecho a un medioambiente sano constituye un interés universal, que se debe tanto a las generaciones presentes y futuras. Ahora bien, el derecho al medioambiente sano también tiene una dimensión individual, en la medida en que su vulneración puede tener repercusiones directas o indirectas sobre las personas debido a su conexidad con otros derechos, tales como el derecho a la salud, la integridad personal o la vida, entre otros (párrafo 57).

En línea con la mayoría de la doctrina, la Corte reconoce que este derecho tiene una doble dimensión de colectivo e individual. Introduce además la idea de que, en su faz colectiva, el derecho a un medioambiente sano importa la protección para las generaciones actuales y futuras, cuestión que resulta clave para la lucha en contra de ciertos fenómenos, sobre todo el cambio climático.

Además de discurrir sobre la naturaleza del derecho, la Corte IDH también nos da luces sobre las obligaciones que para el Estado significa su reconocimiento, citando al grupo de trabajo de San Salvador, para establecer que dichas obligaciones son: «a) garantizar a toda persona, sin discriminación alguna, un medioambiente sano para vivir; b) garantizar a toda persona, sin discriminación alguna, servicios públicos básicos; c) promover la protección del medioambiente; d) promover la preservación del medioambiente, y e) promover el mejoramiento del medioambiente». En seguida, también comparte los criterios que debieran guiar el ejercicio de este derecho: disponibilidad, accesibilidad, sostenibilidad, aceptabilidad y adaptabilidad (párrafo 60).

A continuación, la Corte analiza los derechos conexos con el medioambiente que precisamente consultó Colombia: vida e integridad física. 


\section{Derechos conexos y deberes de los Estados}

relacionados con la vida y la integridad

El principal derecho que se conecta con el medioambiente sano es la vida. La Corte reconoce que, en este contexto, la vida está condicionada por un medioambiente adecuado y en el cual se puede acceder al agua y la alimentación. Reconoce en forma expresa que existe un derecho humano al agua, que está incorporado en este análisis de la conexión entre medioambiente y vida, al señalar que: «Cabe destacar que el acceso al agua incluye el acceso para uso personal y doméstico», que comprende «el consumo, el saneamiento, la colada, la preparación de alimentos y la higiene personal y doméstica» (párrafo 111).

En particular, la Corte IDH lista las que serían las principales obligaciones de los Estados en la protección del derecho a la vida y el medioambiente. Una primera obligación, conexa con el respeto de los derechos humanos y libertades es la de:

Abstenerse de: i) cualquier práctica o actividad que deniegue o restrinja el acceso, en condiciones de igualdad, a los requisitos para una vida digna, como lo son, el agua y la alimentación adecuada, entre otros; y de ii) contaminar ilícitamente el medioambiente de forma que se afecte las condiciones que permiten la vida digna de las personas, por ejemplo, mediante el depósito de desechos de empresas estatales en formas que afecten la calidad o el acceso al agua potable y/o a fuentes de alimentación (párrafo 117).

Esta obligación es interesante, pues integra de forma implícita una idea de justicia ambiental positiva, en el sentido de que se preocupa de la distribución no solo de las cargas que ponemos sobre el medioambiente, sino en especial de los beneficios que el nos otorga, por lo que el agua y la alimentación adecuada, entre otros bienes, deben ser accesibles de manera igualitaria.

En seguida, una segunda obligación para los Estados es adoptar las medidas para proteger y preservar la vida y la integridad de las personas. Estos puntos están relacionados con los principios de prevención y precaución como integrantes del derecho al medioambiente, lo que se desarrollará más adelante. Además, la obligación es desarrollada por la Corte en relación con el daño ambiental, expresando que, si bien el Estado no es responsable por las violaciones de derechos humanos causadas por privados, sí podría serlo en el caso de que: i) las autoridades supieran o debieran saber sobre la existencia de riesgo; y ii) se pueda establecer causalidad entre el daño ambiental significativo y la afectación a la vida y la integridad (párrafo 120).

Lo anterior no obstaría, de acuerdo con la Corte, que los Estados están obligados a garantizar medidas positivas para el ejercicio de derechos. En este punto vuelve al derecho al agua y a la alimentación para ejemplificar con la necesidad de acciones positivas, en los casos en que existan grupos que tengan dificultades en el acceso a ellos (párrafo 120). 


\section{Deberes estatales frente a los posibles daños (principio de prevención)}

Para el cumplimiento de las obligaciones de respetar y garantizar los derechos a la vida y a la integridad personal, en el contexto de la protección del medioambiente, los Estados deben cumplir con un deber general de diligencia, el cual a su vez se traduce, en opinión de la Corte, en una serie de obligaciones generales, tanto frente a los posibles daños ocurridos dentro de su territorio como a los daños que traspasen sus fronteras (párrafo 123).

La primera obligación conlleva el deber de los Estados de prevenir las violaciones a los derechos humanos, a través de medidas de diferente carácter (párrafo 127). En materia ambiental, la Corte identifica que esta obligación ha sido reconocida en el derecho internacional consuetudinario, tal como lo demuestran los casos de la Fundición Trail de 1938 (Estados Unidos con Canadá) ${ }^{4}$ y del Canal de Corfú (Reino Unido con Albania), ${ }^{5}$ que dispone que los Estados tienen el deber de debida diligencia internacional de no causar o permitir que se causen daños a otros Estados (párrafo 128).

Así es como lo ha consignado también el fallo de la Corte Internacional de Justicia en el caso de las plantas de celulosa sobre el Río Uruguay (Argentina con Uruguay). ${ }^{6}$ Este fallo establece que los Estados están obligados a usar todos los medios a su alcance con el fin de evitar que las actividades que se lleven a cabo bajo su jurisdicción causen daños significativos al medioambiente. Esta obligación debe cumplirse bajo un estándar de debida diligencia, el cual debe ser el apropiado y proporcional al grado de riesgo de daño ambiental. ${ }^{7}$

El principio de prevención en materia ambiental también ha sido consagrado en las Declaraciones de Estocolmo de 1972 (principio 21) y de Río de Janeiro de 1992 (principio 2), y obliga a los Estados a «velar por que las actividades efectuadas dentro de su jurisdicción o bajo su control no causen daños al medioambiente de otros Estados o de zonas que estén fuera de los límites de la jurisdicción nacional». De este modo, tal como lo dispone la opinión consultiva de la Corte IDH, tomando en cuenta que con frecuencia no es posible restaurar la situación existente antes de la ocurrencia de un daño ambiental, considera que la prevención «debe ser la política principal respecto de la protección del medioambiente» (opinión Consultiva OC-23/17, párrafo 130).

En conclusión, esta obligación de prevención, a juicio de la Corte, aplica para daños que puedan ocurrir dentro o fuera del territorio del Estado de origen (párrafo 133), pero solo respecto de daños que sean de carácter significativo (párrafo 140), es decir, que

4. Sentencia de la Corte IDH, 16 de abril de 1938 y 11 de marzo de 1941.

5. Sentencia de la Corte Interamericana de Justicia, 9 de abril de 1949.

6. Sentencia del caso Plantas de celulosa sobre el Río Uruguay (Argentina con Uruguay), Corte Interamericana de Justicia, 20 de abril de 2010.

7. Tribunal Internacional del Derecho del Mar, opinión consultiva del 1 de febrero de 2011, párrafo 117. 
requieren «un determinado nivel en los efectos del daño» (párrafo 137), lo cual deberá determinarse en cada caso concreto, con atención a las circunstancias particulares.

A continuación, la Corte IDH señala los deberes mínimos que los Estados deben implementar para cumplir con esta obligación de prevención; i) regular; ii) supervisar y fiscalizar; iii) requerir y aprobar estudios de impacto ambiental; iv) establecer un plan de contingencia, y v) mitigar en casos de ocurrencia de daño ambiental.

En cuanto al deber de regular, y de acuerdo con la jurisprudencia de la Corte IDH, los Estados, tomando en cuenta el nivel de riesgo existente, deben regular las actividades que se desarrollan en su territorio "puedan causar un daño significativo al medioambiente, de manera que disminuya cualquier amenaza a los derechos a la vida y a la integridad personal» (párrafo 149), lo que incluye el deber de regular con claridad los procesos de evaluación de impacto ambiental, a los cuales nos referiremos en específico más adelante.

En segundo lugar, la Corte IDH, tras observar su propia jurisprudencia y la de la Corte Interamericana de Justicia, establece que «los Estados tienen un deber de supervisar y fiscalizar actividades, bajo su jurisdicción, que puedan producir un daño significativo al medioambiente». Por tanto, dispone que deben desarrollar y poner en práctica «mecanismos adecuados e independientes de supervisión y rendición de cuentas» (párrafo 154). Esto incluye mecanismos preventivos, como de sanción y de reparación de daños.

En tercer lugar, la Corte IDH se refiere en detalle a la obligación de los Estados de requerir y aprobar estudios de impacto ambiental, lo cual es una innovación, ya que la Corte hasta el momento solo se había pronunciado respecto de esta obligación en el marco de actividades desarrolladas en territorios de comunidades indígenas. Al respecto, la Corte reconoce que esta obligación ha sido reconocida en la Declaración de Río de 1992, así como en la legislación de numerosos Estados, por lo que advierte que «la obligación de llevar a cabo un estudio de impacto ambiental existe también en relación con cualquier actividad que pueda causar un daño ambiental significativo» o un impacto negativo considerable, como lo señala el principio 17 de la Declaración de Río de 1992. ${ }^{8}$

Además, tomando como referencia la legislación nacional de los diferentes Estados, la jurisprudencia internacional y algunos instrumentos ambientales de soft law relevantes en la materia, ${ }^{9}$ establece que los estudios de impacto ambiental deben hacerse según estándares internacionales y buenas prácticas (párrafos 160-171):

8. Declaración de Río, principio 17: «Deberá emprenderse una evaluación del impacto ambiental, en calidad de instrumento nacional, respecto de cualquier actividad propuesta que probablemente haya de producir un impacto negativo considerable en el medioambiente y que esté sujeta a la decisión de una autoridad nacional competente».

9. Por ejemplo, Abaza, Bisset y Sadler (2004: 52). 
- Llevarse a cabo antes de la actividad o antes del otorgamiento de los permisos: Preferiblemente, éstos deben comenzar antes de que la ubicación y diseño de los proyectos estén decididas.

- Ser desarrollado por entidades independientes bajo la supervisión del Estado: En caso de que los estudios sean hechos por entidades privadas, los Estados deben tomar medidas para asegurar su independencia. Además, «el Estado deberá tomar en cuenta el impacto que puede tener el proyecto en sus obligaciones de derechos humanos» (párrafo 164).

- Abarcar el impacto acumulado que han generado los proyectos existentes y los que vayan a generar los proyectos propuestos.

- Es «recomendable» que los Estados permitan que cualquier persona interesada tenga oportunidad de presentar sus opiniones o comentarios sobre el proyecto o actividad antes que se apruebe, durante su ejecución y después de que se emita el estudio de impacto ambiental (párrafo 168).

- En casos de proyectos que puedan afectar el territorio de comunidades indígenas, los estudios de impacto ambiental y social deben respetar sus tradiciones y cultura.

- Determinar y precisar, mediante legislación o mediante el proceso de autorización del proyecto, el contenido específico que se requiere para el estudio de impacto ambiental, tomando en cuenta la naturaleza y magnitud del proyecto y la posibilidad de impacto que tendría en el medioambiente.

En cuarto lugar, el principio de prevención obliga al Estado a actuar antes de que ocurran emergencias y desastres ambientales. Así, señala que el Estado de origen debe tener un plan de contingencia para responder a emergencias o desastres ambientales que incluya «medidas de seguridad y procedimientos para minimizar las consecuencias de dichos desastres» (párrafo 171). Por último, si el incidente ocurre a pesar de haberse tomado todas las medidas preventivas del caso, el Estado de origen debe asegurarse de que se tomen las medidas apropiadas para mitigar el daño ambiental, y debe, para esto, «utilizar la mejor tecnología y ciencia disponible» (párrafo 172).

\section{Principio de precaución}

La segunda obligación de diligencia de los Estados frente a los daños ambientales tiene relación con el deber de precaución. Este deber se encuentra reconocido como principio en la Declaración de Río, que señala:

Con el fin de proteger el medioambiente, los Estados deberán aplicar ampliamente el criterio de precaución conforme a sus capacidades. Cuando haya peligro de daño 
grave o irreversible, la falta de certeza científica absoluta no deberá utilizarse como razón para postergar la adopción de medidas eficaces en función de los costos para impedir la degradación del medio ambiente (principio 15).

Para establecer esta obligación, la Corte alude, además, a diversos tratados internacionales que contienen el principio de precaución respecto de distintas materias. Asimismo, reconoce que diferentes Estados de la región incluyen el principio de precaución dentro de su legislación o que éste ha sido reconocido en la jurisprudencia, mencionando en forma expresa el caso de Chile, ${ }^{10}$ aunque advirtiendo que el contenido del principio de precaución varía dependiendo del instrumento que lo consagra. Como explica la Corte, el principio de precaución, en materia ambiental, se refiere a las medidas que se deben adoptar «en casos donde no existe certeza científica sobre el impacto que pueda tener una actividad en el medio ambiente» (párrafo 175).

Por tanto, la Corte IDH entiende que los Estados deben actuar según principio de precaución y adoptar medidas «eficaces», a efectos de la protección del derecho a la vida y a la integridad personal, en casos en que «haya indicadores plausibles que una actividad podría acarrear daños graves e irreversibles al medioambiente, aun en ausencia de certeza científica» (párrafo 180).

\section{Obligación de cooperación}

Por último, la Corte IDH se refiere a la última de las obligaciones «sustantivas» de diligencia ambiental, cual es, la de los Estados de cooperar internacionalmente y de buena fe para la protección de daños contra el medioambiente, sobre todo en materia de recursos compartidos.

\section{El Acuerdo de Escazú como nueva herramienta para la implementación de los derechos de acceso en materia ambiental}

\section{El principio 10 de la Declaración de Río y las obligaciones «de procedimiento» en el contexto de la protección ambiental}

El reconocimiento e implementación del derecho a un medioambiente sano requiere de mecanismos concretos para garantizar su pleno ejercicio. Dentro de éstos, el acceso a la información, a la participación pública en la toma de decisiones ambientales y el acceso a la justicia ambiental (los «derechos de acceso»), son considerados instrumentos imprescindibles para la concreción de este derecho. ${ }^{11}$

10. Corte Suprema, rol 14.209-201, considerando 10.

11. Así lo ha reconocido el relator especial sobre los derechos humanos y el medioambiente, John Knox, en sus diferentes informes. Véase, por ejemplo, «Informe sobre recopilación de buenas prácticas en el cumplimiento de las obligaciones de derechos humanos relativas a la protección del medioam- 
Siguiendo esta línea, la opinión consultiva de la CIDH identifica un grupo de obligaciones como «instrumentales o de procedimiento» (párrafos 64 y 211), en la medida en que permiten la satisfacción de otros derechos de la Convención y que, en materia ambiental, respaldan una mejor formulación de las políticas ambientales.

Estas obligaciones se derivan de ciertos derechos de la Convención Americana, como los derechos a la libertad de expresión y asociación, a la información, a la participación en la toma de decisiones y a un recurso efectivo (párrafos 64 y 211), por lo que, si bien tienen una relación procedimental con el derecho humano al medioambiente, son también derechos sustantivos en sí mismos.

Estos derechos también han sido incorporados en diversos instrumentos internacionales de medioambiente, en particular, la ya mencionada Declaración de Río de 1992, la cual dispone en su principio 10 que: «El mejor modo de tratar las cuestiones ambientales es con la participación de todos los ciudadanos interesados, en el nivel que corresponda».

Sin embargo, los desarrollos más importantes de estas obligaciones se han dado por medio de acuerdos regionales. El primero ocurrió en 1998, cuando los Estados miembros de la Comisión Económica para Europa (CEPE) adoptaron la Convención sobre el Acceso a la Información, la Participación del Público en la Toma de Decisiones y el Acceso a la Justicia en Asuntos Ambientales (Convenio de Aarhus). Este acuerdo se encuentra abierto a la ratificación de cualquier Estado miembro de Naciones Unidas. ${ }^{12}$

En nuestra región, tanto la opinión consultiva de la Corte IDH como los trabajos del Relator de Naciones Unidas sobre Derechos Humanos y Medio Ambiente, John Knox, se refieren al proceso de negociación del instrumento regional sobre los derechos de acceso a la información, participación y justicia en asuntos ambientales en América Latina y el Caribe, que concluyó en marzo de 2018 con el Acuerdo de Escazú.

Así, este instrumento regional recoge las principales obligaciones y mecanismos que en materia de derechos humanos se le exige a los Estados para asegurar el derecho al medioambiente sano, lo que genera así una especial vinculación entre los derechos y mecanismos que este acuerdo plantea, con las recomendaciones que hace la Corte IDH en la ya señalada opinión consultiva.

biente», Consejo de Derechos Humanos de Naciones Unidas, A/HRC/28/61, 3 de febrero de 2015, p. 7, disponible en http://bit.ly/36ggVVZ.

12. Artículo 19.3: «Todo Estado, además de los mencionados en el párrafo 2 supra, que sea miembro de las Naciones Unidas, podrá adherirse a la Convención con el acuerdo de la Reunión de las Partes». 


\section{El proceso de negociación del Acuerdo de Escazú}

En noviembre de 2014, estos países aprobaron la Decisión de Santiago, mediante la cual iniciaron la discusión de un instrumento regional, proceso que culminó con la adopción del Acuerdo Regional sobre el Acceso a la Información, la Participación Pública y el Acceso a la Justicia en Asuntos Ambientales en América Latina y El Caribe (o Acuerdo de Escazú), en Escazú, Costa Rica, el 4 de marzo de 2018. ${ }^{13}$

El Acuerdo de Escazú es el primer tratado vinculante adoptado por los países de América Latina y el Caribe que busca la implementación del principio 10 de la Declaración de Río o los derechos de acceso (artículo 2), y el único en el mundo en incorporar, además, disposiciones específicas para garantizar un entorno seguro y propicio para los defensores de derechos humanos en asuntos ambientales (artículo 9). El objetivo que se propone es:

Garantizar la implementación plena y efectiva en América Latina y el Caribe de los derechos de acceso [...], así como la creación y el fortalecimiento de las capacidades y la cooperación, contribuyendo a la protección del derecho de cada persona, de las generaciones presentes y futuras, a vivir en un medioambiente sano y al desarrollo sostenible (artículo 1).

Se reconoce el carácter instrumental de los derechos de acceso para la efectiva realización del derecho a un medioambiente sano y también de los derechos humanos. ${ }^{14}$ Además, como expresa su preámbulo y como reconoce la propia Corte IDH, se entiende que los derechos de acceso están relacionados entre sí y son interdependientes, «por lo que todos y cada uno de ellos se deben promover y aplicar de forma integral y equilibrada».

El Acuerdo Regional se abrió a la firma de los 33 países de América Latina y el Caribe el 27 de septiembre de 2018 en la sede de Naciones Unidas en Nueva York El acuerdo fue firmado por 14 países durante elmismo día de su apertura a firma, alcanzando a 22 firmantes en los meses posteriores. Sin embargo, a la fecha ha sido ratificado solo por seis países. ${ }^{15}$

13. Las copias auténticas del Acuerdo Regional están disponibles en el sitio web de Cepal, en https:// bit.ly/2szN2Bi.

14. Señala el preámbulo en su primera página: «Convencidas de que los derechos de acceso contribuyen al fortalecimiento, entre otros, de la democracia, el desarrollo sostenible y los derechos humanos».

15. Se requiere la ratificación de once Estados para entrar en vigor (artículos 21 y 22 del Acuerdo de Escazú). 


\section{Sobre el derecho de acceso a la información en materia ambiental}

Puede definirse el derecho de acceso a la información como el derecho a «acceder a datos, registros y todo tipo de informaciones en poder de entidades públicas y empresas privadas que ejercen gasto público o ejercen funciones de autoridad, con las excepciones taxativas que establezca la ley, en una sociedad democrática» (Nava Gomar, Luna Pla y Villanueva, 2006: 13). En materia ambiental, en específico, el principio 10 de la Declaración de Río establece que «toda persona deberá tener acceso adecuado a la información sobre el medioambiente de que dispongan las autoridades públicas, incluida la información sobre los materiales y las actividades que encierran peligro en sus comunidades».

Este principio es citado por la Corte IDH en su opinión consultiva en el contexto de la protección del medioambiente. La Corte estableció que los Estados tienen la obligación de garantizar el derecho al acceso a la información relacionada con posibles afectaciones al medioambiente (párrafo 225), la cual tiene su fuente normativa en el artículo 13 del Pacto de San José, sobre la «libertad de pensamiento y de expresión».

Además, en el marco de la protección ambiental, esta obligación implica tanto la provisión de mecanismos y procedimientos para que las personas individuales soliciten la información (transparencia pasiva), como la recopilación y difusión activa de información por parte del Estado (transparencia activa). Por último, este derecho no es absoluto, por lo que admite restricciones, siempre y cuando estén previamente fijadas por ley, respondan a un objetivo permitido por la Convención Americana y sean necesarias y proporcionales para responder a un interés general en una sociedad democrática (párrafo 225).

Asimismo, el Acuerdo de Escazú reconoce y regula en detalle en el artículo 5 el derecho del público - o los ciudadanos- de acceder a la información ambiental «que está en su poder, bajo su control o custodia» (transparencia pasiva) y su procedimiento, de acuerdo con el principio de máxima publicidad. Para ello, define la información ambiental como:

Cualquier información escrita, visual, sonora, electrónica o registrada en cualquier otro formato, relativa al medioambiente y sus elementos y a los recursos naturales, incluyendo aquélla que esté relacionada con los riesgos ambientales y los posibles impactos adversos asociados que afecten o puedan afectar el medioambiente y la salud, así como la relacionada con la protección y la gestión ambientales (artículo 2 letra c).

Por último, el Acuerdo se refiere en su artículo 6.1 a la obligación de generación y divulgación de información ambiental de manera periódica de acuerdo con las capacidades nacionales (transparencia activa). Además, dispone el deber de contar con sistemas de información ambiental actualizados, así como un registro de emisiones 
y transferencia de contaminantes al aire, agua, suelo y subsuelo, y de materiales y residuos bajo su jurisdicción (artículos 6.3 y 6.4).

\section{Sobre el derecho a la participación ciudadana en materia ambiental}

Respecto de asuntos ambientales, la participación representa - al menos- un mecanismo para integrar las preocupaciones y el conocimiento de la ciudadanía en las decisiones de políticas públicas que afectan al medioambiente (Cepal, 2013: 7).

Lo anterior es reafirmado por la misma Corte IDH en su opinión consultiva, que señala que este derecho es uno de los «pilares fundamentales» de los derechos de acceso (párrafo 226) y que los Estados tienen la obligación de garantizar el derecho a la participación pública de las personas bajo su jurisdicción, consagrado en el artículo 23.1.a de la Convención, en la toma de decisiones y políticas que pueden afectar el medioambiente (párrafo 227).

A juicio de la Corte, la participación debe asegurarse desde las primeras etapas del proceso de adopción de decisiones e informar al público sobre estas oportunidades de participación (párrafo 232). Además, ésta debe hacerse sin discriminación, de manera equitativa, significativa y transparente, para lo cual antes debe haberse garantizado el acceso a la información relevante (párrafo 231).

Asimismo, el Acuerdo de Escazú establece en su artículo 7 la obligación de asegurar el derecho de participación del público y a implementar «una participación abierta e inclusiva en los procesos de toma de decisiones ambientales», lo que incluye las relativas a proyectos o procesos de autorizaciones ambientales (artículo 7.2) y otras relativas al ordenamiento del territorio y la elaboración de políticas, estrategias, planes, programas, normas y reglamentos (artículo 7.3), que tengan o puedan tener un significativo impacto sobre el medio ambiente.

Por otra parte, el Acuerdo va un poco más allá, al especificar los efectos de la participación y establecer que «el derecho del público a participar en los procesos de toma de decisiones ambientales incluirá la oportunidad de presentar observaciones por medios apropiados y disponibles» y que «antes de la adopción de la decisión, la autoridad pública que corresponda tomará debidamente en cuenta el resultado del proceso de participación» (artículo 7.7).

Para estos efectos, el Acuerdo regula, tal como lo dispone la Corte IDH, la oportunidad de la participación, la cual debe darse desde «etapas iniciales» (artículo 7.4), con plazos que deben ser «razonables» (artículo 7.5), con la información que debe entregarse para su procedimiento (artículo 7.6), la notificación de la decisión final (artículo 7.8), y las medidas de apoyo para personas y grupos en situación de vulnerabilidad (artículo 7.14), entre otras medidas. 


\section{Sobre el derecho de acceso a la justicia ambiental}

A través del acceso a la justicia se le reconoce a la persona la capacidad y legitimación de actuar ante los órganos competentes establecidos por ley, tanto para garantizar el acceso a la información ambiental y a la participación, como para solicitar de manera directa la defensa del medioambiente afectado. ${ }^{16}$

En cuanto a la conceptualización del acceso a la justicia ambiental, Brañes (2000: 40) sostiene que este derecho puede ser entendido como «la posibilidad de obtener la solución expedita y completa por las autoridades judiciales de un conflicto jurídico de naturaleza ambiental, lo que supone que todas las personas están en igualdad de condiciones para acceder a la justicia y para obtener resultados individual o socialmente justos».

El principio 10 de la Declaración de Río de Janeiro recoge esta idea y establece que los Estados deberán proveer «acceso efectivo a los procedimientos judiciales y administrativos, entre éstos el resarcimiento de daños y los recursos pertinentes». Por lo tanto, la obligación de asegurar el acceso a la justicia tiene que ver con remover aquellas barreras que impiden a las personas o víctimas de daños ambientales acceder a procedimientos judiciales o administrativos, para obtener soluciones expeditas y justas.

Con el objetivo de superar parte de estos problemas, de acuerdo con el Relator de Naciones Unidas sobre Medio Ambiente y Derechos Humanos, los Estados «han adoptado una amplia variedad de buenas prácticas, estableciendo desde tribunales ambientales especiales hasta normas de procedimiento que facilitan el acceso a los tribunales de los denunciantes de cuestiones ambientales». ${ }^{17}$

Por su parte, la Corte IDH señala en esta materia que los Estados tienen la obligación de garantizar el acceso a la justicia, en relación con las obligaciones estatales para la protección del medio ambiente (opinión consultiva OC-23/17, párrafos 233-234). Ahondando en ello, la Corte establece que, en casos de daños ambientales transfronterizos, se debe garantizar el acceso a la justicia a las personas afectadas por daños ambientales originados en el territorio del Estado responsable, aun cuando estas personas se encuentren o residan fuera del mismo (párrafos 238 y 240). Sin embargo, la Opinión Consultiva no especifica los requisitos de dicho acceso.

El Acuerdo de Escazú, en cambio, es el primer instrumento vinculante de la región que regula la materia y establece que los Estados deben garantizar un acceso a

16. «Programa Interamericano de Capacitación Judicial sobre el Estado de Derecho Ambiental 3: Aspectos substantivos del derecho ambiental», Organización de los Estados Americanos, 2016, p. 17, disponible en https://bit.ly/2QDPmPW.

17. «Informe sobre recopilación de buenas prácticas en el cumplimiento de las obligaciones de derechos humanos relativas a la protección del medioambiente», Consejo de Derechos Humanos de Naciones Unidas, A/HRC/28/61, 3 de febrero de 2015, p. 7, disponible en http://bit.ly/36ggVVZ. 
órganos judiciales y administrativos, de acuerdo con las garantías del debido proceso, para impugnar y recurrir decisiones, actos u omisiones relacionadas con solicitudes de acceso a la información, participación pública, o que afecten o pueden afectar el medioambiente o vulnerar normas jurídicas relacionadas con éste (artículos 8.1 y 8.2).

Para este fin, establece que los Estados deben contar, por ejemplo, con órganos con conocimientos especializados, procedimientos efectivos, oportunos, públicos, transparentes, imparciales y sin costos prohibitivos, garantizar la legitimación activa amplia en defensa del medioambiente según la legislación nacional, disponer de medidas para facilitar la prueba del daño ambiental, mecanismos de ejecución y de cumplimiento oportunos de las decisiones, y mecanismos especiales de apoyo a personas y grupos en situación de vulnerabilidad, entre otras medidas.

\section{Conclusiones y desafíos del derecho ambiental chileno}

Tanto la opinión consultiva de la Corte IDH como el Acuerdo de Escazú constituyen piedras fundamentales del avance en la construcción de un derecho humano al ambiente en la región, y así también en Chile. En el caso particular de nuestro país, existen en ambos documentos menciones que servirán para superar algunas de las discusiones doctrinarias y jurisprudenciales clásicas, por lo que la opinión consultiva de la Corte IDH sirve como un hito que consolida la relevancia de los derechos que en el Acuerdo se establecen.

En primer lugar, el reconocimiento del derecho al medioambiente como derecho humano autónomo constituye un avance en el sentido de las cuestiones que deben ser probadas en un determinado procedimiento cuando se está alegando la afectación del medioambiente. Aun desde la visión evidentemente antropocéntrica que supone el lenguaje de los derechos humanos, de todas formas, su autonomía pone en una mejor posición a las personas para defender al medioambiente en sí, desde una mirada humana, pero no necesariamente conectada con afectaciones a otros derechos como la vida y la salud.

Este ejercicio supone además comprender dos cuestiones que son de muy incipiente discusión en nuestra doctrina: el derecho a la alimentación y el derecho humano al agua, ambos conexos de manera inexorable con el derecho al medioambiente y, por lo tanto, reconocidos por la Corte IDH como potenciales conectados por la afectación del medioambiente. En el caso del derecho humano al agua, no tenemos dudas de que la discusión de política pública deberá abordarlo de manera más seria en el corto plazo, pues las urgencias en este sentido las dicta el cambio climático y la sobreexplotación, entre los demás dilemas de la regulación de aguas (Costa Cordella, 2016).

En seguida, la conexión del derecho al medioambiente con los principios de los cuales proviene y que le sirven de guía es reconocida por la Corte IDH, dando sen- 
tido a las normas ambientales y las obligaciones de los Estados sobre todo desde la protección del medioambiente en clave preventiva y precautoria. Si bien estos principios han tenido un tratamiento doctrinario y jurisprudencial en Chile, nos parece que el reconocimiento expreso que hace la Corte servirá para profundizarlos. Esto, sobre todo en lo que dice relación con el principio precautorio, que en general ha sido menos aplicado de lo que su importancia en materia de derecho ambiental propone y hace suponer.

Por último, y en lo que es más potente, los derechos de acceso en materia ambiental entran en una nueva era, que propone una colaboración entre los ciudadanos y el Estado que es mucho mayor a la que habíamos visto hasta el momento, así como una posibilidad mayor de control de las actividades estatales y privadas que generan daños al medioambiente. Los derechos de acceso, como dijimos, tienen una reconocida conexión con el derecho humano al medioambiente, y tienen también vida propia y un sustento específico. La opinión consultiva de la Corte IDH versa más bien sobre lo primero y el Convenio de Escazú se acerca más a lo segundo. Existe, sin embargo, mucho camino por andar desde este reconocimiento internacional expreso, al efectivo respeto e implementación de estos derechos en el ordenamiento jurídico nacional.

El modelo de los derechos de acceso ha sido claramente una novedad en el panorama legal, y si bien su propagación ha sido lenta, también ha tenido notables salientes. Además del Convenio de Aarhus y el Acuerdo de Escazú, el modelo del principio 1o ha llegado a constitucionalizarse. Este proceso, como reconocen May y Daly (2015: 77), obedecería a un ánimo de permitir un ulterior avance de la protección del medio ambiente. En particular, el derecho a la participación en cuestiones ambientales se encontraba reconocido al 2015 en las constituciones de Brasil, Colombia, Ecuador, Eritrea, Etiopía, Finlandia, Francia, Islandia, Kosovo, Polonia, Tailandia y Zambia (May y Daly, 2015: 373-374; Gellers, 2017; Knox y Pejan, 2018).

El adecuado reconocimiento de los derechos de acceso, en el marco de la conceptualización del derecho humano al medioambiente, supone un avance en términos de gobernanza del territorio, de relación entre los ciudadanos y el Estado, y probablemente tiende hacia mejores niveles de justicia distributiva. Tanto la opinión consultiva de la Corte IDH como el Convenio de Escazú nos guían en ese sentido. Desde este punto, creemos que futuros trabajos podrán analizar cambios normativos específicos que se requieren para adecuar nuestro derecho ambiental a las exigencias que este nuevo marco impone.

\section{Referencias}

AвAzA, Hussein, Ron Bisset y Barry Sadler (2004). Environmental impact assessment and strategic environmental assessment: Towards an integrated approach. Nairobi: PNUMA. 
Aguilar Cavallo, Gonzalo (2016). «Las deficiencias de la fórmula "derecho a vivir en un medio ambiente libre de contaminación" en la Constitución chilena y algunas propuestas para su revisión». Estudios constitucionales, 14 (2): 365-416. DOI: 10.4067/So718-52002016000200012.

Aristegui, Juan Pablo (2010). «La protección de medio ambiente en la jurisprudencia de algunos órganos de protección de derechos humanos». Justicia Ambiental, 2: 23-48.

Bermúdez Soto, Jorge (2000). «El derecho a vivir en un medio ambiente libre de contaminación». Revista de Derecho de la Pontificia Universidad Católica de Valparaíso, 21: 9-25. Disponible en http://bit.ly/35gc2uX.

Bertelsen Repetto, Raúl (1998). «El recurso de protección y el derecho a vivir en un medio ambiente libre de contaminación: Examen de quince años de jurisprudencia». Revista Chilena de Derecho, 25 (1): 139-174. Disponible en http://bit. ly/2Fbmqcz.

Bonine, John E. y Svitlana Kravchenko (2012). «La interpretación de los derechos humanos para la protección del medio ambiente en la Corte Europea de Derechos Humanos». Justicia Ambiental, 4: 21-72.

Boyd, David R. (2011). The environmental rights revolution: A global study of constitutions, human rights, and the environment. Vancouver: UBC Press.

BRAÑES, Raúl (2000). «El acceso a la justicia ambiental en América Latina: Derecho ambiental y desarrollo sostenible». En Simposio Judicial sobre Derecho Ambiental y Desarrollo Sostenible: El Acceso a la Justicia en América Latina. 26 al 28 de enero de 2000, Ciudad de México: Programa de Naciones Unidas para el Medio Ambiente y Procuraduría Federal de Protección al Ambiente, Gobierno de México.

Cepal, Comisión Económica para América Latina y el Caribe (2013). Situación actual, perspectivas y ejemplos de buenas prácticas. Santiago. Disponible en https:// bit.ly/2MKOZBQ.

Costa Cordella, Ezio (2016). «Diagnóstico para un cambio: Los dilemas de la regulación de las aguas en Chile». Revista Chilena de Derecho, 43 (1): 335-354. DOI: 10.4067/So718-34372016000100014.

GELLERS, Joshua (2017). The global emergence of constitutional environmental rights. Nueva York: Routledge.

Guzmán Rosen, Rodrigo (2012). Derecho ambiental chileno: Principios, instituciones, instrumentos de gestión. Santiago: Planeta Sostenible.

JARIA I MANZANO, Jordi (2011). La cuestión ambiental y la transformación de lo público. Valencia: Tirant lo Blanch.

Knox, John y Ramin Pejan (2018). The human right to a healthy environment. Nueva York: Cambridge University Press. 
MaY, James y Erin Daily (2015). Global environmental constitucionalism. Nueva York: Cambridge University Press.

Nava Gomar, Salvador, Issa Luna Pla y Ernesto Villanueva (2006). Derecho de acceso a la información pública parlamentaria. Ciudad de México: Miguel Ángel Porrúa.

PNUMA, Programa de las Naciones Unidas para el Medio Ambiente (2014). Human rights and the environment: Regional consultation on the relationship between human rights obligations and environmental protection, with a focus on constitutional environmental rights. Sudáfrica, 23-24 de enero 2014. Disponible en http://bit. ly/2GhiqYt.

VÁsquez Márquez, José Ignacio (2014). «Pasado y futuro del medio ambiente como derecho fundamental». Revista de Derecho Público, 80: 143-162. DOI: 10.5354/0719-5249.2014.33323.

\section{Sobre los autores}

Ezio Costa Cordella es abogado de la Universidad de Chile. Magíster en Regulación por la London School of Economics, Reino Unido, y doctorando en Derecho por la Universidad de Chile. Investigador del Centro de Regulación y Competencia (RegCom) y del Instituto Milenio para las Imperfecciones de Mercado y las Políticas Públicas (MIPP), ambos de la Universidad de Chile. Director ejecutivo de la ONG FIMA. Su correo electrónico es costa@fima.cl.

Gabriela Burdiles Perucci es abogada de la Universidad Católica de Chile. Magíster en Estudios Internacionales de la Universidad de Chile. Magíster en Derechos Humanos, London School of Economics. Profesora de la Clínica de Derecho Ambiental, Universidad Central de Chile. Directora de proyectos de la ONG FIMA. Su correo electrónico es burdiles@fima.cl. 
